\title{
Ocular TGF- $\beta$, Matrix Metalloproteinases, and TIMP-1 Increase with the Development and Progression of Diabetic Retinopathy in Type 2 Diabetes Mellitus
}

\author{
Lucia Saucedo $\mathbb{D}^{1}{ }^{1}$ Isabel B. Pfister ${ }^{\mathbb{D}}{ }^{1}$ Souska Zandi $\mathbb{D}^{1,2}$ Christin Gerhardt ${ }^{1}{ }^{1}{ }^{1}$ \\ and Justus G. Garweg (ii) ${ }^{1,2}$ \\ ${ }^{1}$ Swiss Eye Institute, Rotkreuz and Retina Clinic, Berner Augenklinik am Lindenhofspital, 3012, Switzerland \\ ${ }^{2}$ Department of Ophthalmology, Inselspital, Bern University Hospital, University of Bern, 3012, Switzerland \\ Correspondence should be addressed to Justus G. Garweg; justus.garweg@augenklinik-bern.ch
}

Received 29 April 2021; Accepted 4 June 2021; Published 28 June 2021

Academic Editor: Shin-ichi Yokota

Copyright (C) 2021 Lucia Saucedo et al. This is an open access article distributed under the Creative Commons Attribution License, which permits unrestricted use, distribution, and reproduction in any medium, provided the original work is properly cited.

\begin{abstract}
Diabetic retinopathy (DR) is a sight-threatening late complication of diabetes mellitus (DM). Even though its pathophysiology has not been fully elucidated, several studies suggested a role for transforming growth factor- (TGF-) $\beta$, matrix metalloproteinases (MMPs), and tissue inhibitors of matrix metalloproteinase (TIMP) in the onset and progression of the disease. Consequently, the aim of this study was to analyze the concentrations of TGF- $\beta 1$, TGF- $\beta 2$, TGF- $\beta 3$, MMP-3, MMP-9, and TIMP- 1 in patients with different stages of DR in order to identify stage-specific changes in their concentrations during the progression of the disease. Serum and aqueous humor $(\mathrm{AH})$ samples were collected during intraocular surgery, and eyes were classified into the following groups: healthy controls $(n=17)$, diabetic patients with non-apparent $\mathrm{DR}(n=23)$, mild/moderate nonproliferative DR (NPDR) $(n=13)$, and advanced NPDR/proliferative DR (PDR) without vitreal hemorrhage $(n=14)$. None of the patients had been under anti-VEGF or laser treatment within six months prior to surgery. In the AH, TGF- $\beta 1$ levels increased in advanced NPDR/PDR by a factor of 5.5 compared to the control group. Similarly, an increase in MMP-3 and TIMP- 1 levels in the $\mathrm{AH}$ was evident in the later stages of $\mathrm{DR}$, corresponding to a 7.7- and 2.4-fold increase compared to the control group, respectively, whereas serum levels of the studied proteins remained similar. In conclusion, increased concentrations of TGF- $\beta 1$, MMP-3, and TIMP-1 in the AH, but not in the serum, in advanced NPDR/PDR indicate that the intraocular regulation for these cytokines is independent of the systemic one and suggest their involvement in the progression of DR.
\end{abstract}

\section{Introduction}

Diabetic retinopathy (DR) is one of the most common late complications of diabetes mellitus (DM) and the leading cause of vision loss among the working age population [1]. It is estimated that one in three people with DM has DR and that one in 10 will develop a sight-threatening form of the disease, including diabetic macular edema (DME) or proliferative DR (PDR) [2]. The most relevant factors associated with the prevalence and progression of DR are duration of diabetes, glycemic control, and hypertension $[3,4]$.

Transforming growth factor- (TGF-) $\beta$ is a pleiotropic cytokine involved in cellular proliferation, differentiation, and migration, as well as in the production and degradation of extracellular matrix (ECM) components [5]. Three isoforms of TGF have been identified and are encoded by different genes but share $71-79 \%$ homology [6]. Even though the three isoforms of TGF- $\beta$ have overlapping spatial and temporal expression patterns in several tissues, in vivo studies (as well as the isoform-specific knockout models) suggest that they may elaborate different tissue-specific functions $[7,8]$. In the healthy retina, TGF- $\beta$ is fundamental for the maintenance of vascular homeostasis, as it acts as a survival factor, inhibiting endothelial cell (EC) growth and migration and inducing differentiation and growth arrest in pericytes. Pathological TGF- $\beta$ signaling has been suggested as one of the key mechanisms involved in the onset of DR $[9,10]$. Dysregulation of TGF- $\beta$ signaling leads to increased production 
of ECM components, which results in thickening of the basal membrane (BM) [11], one of the early hallmarks of DR. In vitro, TGF- $\beta$ decreases the expression of VE-cadherin and claudin-5, leading to an increase in vascular permeability [12]. Moreover, inhibition of TGF- $\beta$ signaling in experimental models is linked to vessel destabilization $[13,14]$.

In a similar way, matrix metalloproteinases (MMPs) have been linked to the pathophysiology of DR. MMPs constitute a multigene family of proteolytic zinc-dependent endopeptidases, which encompass at least 23 members in humans [15]. MMP activity is closely regulated by their endogenous inhibitors, tissue inhibitors of matrix metalloproteinase (TIMP), whose family encompasses four members. TIMP-1 is a strong inhibitor of most MMPs, including MMP-1, MMP2, MMP-3, and MMP-9, and can, in addition, bind to proMMP-9, blocking the activation of the enzyme [16]. The balance between TIMP-1 and MMPs may be critical for tissue homeostasis in DR. Several studies have demonstrated the contribution of MMPs to the regulation of vascular permeability by degradation of junction proteins, namely, occluding $[17,18]$. In vitro, the secretion of MMPs is induced by TGF- $\beta$, partially explaining the breakdown of the bloodretina barrier in advanced disease [19]. Latent TGF- $\beta$, in turn, is activated by MMP-2 and MMP-9. This indicates the complex interplay between TGF- $\beta$ isoforms and MMPs in angiogenesis in general [20] and the progression of DR in particular.

Among the MMPs, MMP-2 and MMP-9 have been the most studied in the context of DR. Their involvement in the apoptosis of pericytes, ECs, and Müller cells [21, 22], as well as in the increase in vascular permeability $[17,23]$ and angiogenesis [24], has been demonstrated. To date, only limited information is available regarding MMP-3 in the retina in health and disease. The fact that it cleaves several ECM and $\mathrm{BM}$ components and is involved in the activation of other MMPs, namely, MMP-9 [25, 26], suggests a potential upstream regulatory role in DR. Interestingly, a pathological role of MMPs in several neurological diseases has been associated with its capability to degrade tight junction proteins and to compromise the blood-brain barrier [27, 28].

If TGF- $\beta 1$, TGF- $\beta 2$, TGF- $\beta 3$, MMP-3, MMP-9, and TIMP-1 are involved in the pathogenesis of DR, as outlined above, we hypothesized that their intraocular and eventually also systemic concentrations might be linked to the severity of diabetes and DR. Therefore, this study is aimed at analyzing their concentrations in parallel samples of serum and aqueous humor $(\mathrm{AH})$ from patients with untreated $\mathrm{DR}$ and healthy controls in order to identify stage-specific differences in their concentrations during the progression of DR.

\section{Materials and Methods}

2.1. Patients. This retrospective analysis refers to a total of 17 healthy individuals without any known systemic or ocular disease, except for requiring intraocular surgery (cataract, macular hole, or epiretinal membrane), and 50 patients with type 2 DM with or without DR undergoing intraocular surgery for the same reasons at a single institution (Clinic for Vitreoretinal Diseases, Berner Augenklinik am Lindenhof- spital, Bern, Switzerland). Parallel samples of AH and serum were collected between 2013 and 2018 in a random fashion from healthy controls and diabetics irrespective of the severity and treatment of ocular and systemic diseases at the beginning of surgery. Any sample from patients meeting the inclusion criteria was included irrespective of the diabetic retinopathy stage if none of the following exclusion criteria were present: type $1 \mathrm{DM}$, history of any systemic malignant, vascular, or inflammatory comorbidity (e.g., rheumatic or autoimmune diseases), systemic treatments involving corticosteroids or immunomodulatory drugs, intravitreal or panretinal laser photocoagulation treatment within 6 months prior to surgery, vitreous hemorrhage, uveitis, glaucoma, or any unassociated concomitant retinal pathology.

The stage of DR was independently determined by a graduated ophthalmologist blinded to the study protocol based on the results of dilated stereobiomicroscopy of the anterior and posterior segments of the eye, macular optical coherence tomography (OCT), and widefield fundus images $\left(\right.$ Optos $\left.^{\circledR}\right)$ according to the International Clinical Diabetic Retinopathy Disease Severity Scale [29]. Ocular disease was correspondingly categorized as diabetes with non-apparent DR, mild/moderate non-proliferative DR (NPDR), and advanced DR (advanced NPDR/PDR).

This study was fully compliant with the tenets of the Declaration of Helsinki in its latest version and approved by the local Ethics Committee of the University of Bern (Ref. no 152/08). General informed consent was obtained from all study participants after the explanation of the nature and possible consequences of the study.

2.2. Determination of Target Protein Concentrations. After collection, serum and $\mathrm{AH}$ samples were immediately stored at $-80^{\circ} \mathrm{C}$ until analysis. Samples were analyzed using a multiplex bead system, as previously described [30]. For the determination of target protein concentrations, the following assays were used: TGF- $\beta 1$, TGF- $\beta 2$, and TGF- $\beta 3$ (Bio-Plex Pro TGF- $\beta$ 3-Plex Assay, Bio-Rad, Hercules, CA, USA) and MMP-3, MMP-9, and TIMP-1 (Human Custom ProcartaPlex, Thermo Fisher, Waltham, Massachusetts, USA). The aforementioned TGF- $\beta$ assay measures the active form of three TGF- $\beta$ isoforms. The plates were read using the BioPlex FLEXMAP 3D system with xPONENT 4.2 software (Bio-Rad, Hercules, CA, USA). All procedures were performed following the manufacturer's instructions and in a blinded manner by an experienced technician.

2.3. Statistical Analysis. Measurements ranging below the lower limit of quantification (LLOQ) of the assay were replaced by half the value of the LLOQ specified for the corresponding target protein by the manufacturer, as previously established [31]. Outliers were identified by a box plot analysis (box whisker plot), and extreme outliers (more than three box lengths away from the edge) were excluded from the statistical analysis.

The Shapiro-Wilk test was applied to determine the normal distribution of the data. Since most data did not meet the criteria for normal distribution, the nonparametric KruskalWallis test was used for intergroup comparison of continuous data and the chi-squared test of independence to evaluate 
TABLE 1: Patient baseline characteristics.

\begin{tabular}{|c|c|c|c|c|c|}
\hline & $\begin{array}{l}\text { Healthy controls } \\
\qquad(n=17)\end{array}$ & $\begin{array}{c}\text { Non-apparent DR } \\
(n=23)\end{array}$ & $\begin{array}{c}\text { Mild/moderate NPDR } \\
(n=13)\end{array}$ & $\begin{array}{c}\text { Advanced NPDR/PDR } \\
(n=14)\end{array}$ & $p$ value \\
\hline Age (years; mean $\pm S D$ ) & $64.6 \pm 10.8$ & $71.6 \pm 9.6$ & $72.1 \pm 7.9$ & $69.1 \pm 9.5$ & 0.14 \\
\hline $\begin{array}{l}\text { Gender } \\
\text { F (\%) }\end{array}$ & $16(94.1)$ & $11(47.8)$ & $6(46.2)$ & $7(50)$ & $0.01^{*}$ \\
\hline Duration of diabetes (years; mean $\pm S D$ ) & N/A & $15.0 \pm 12.9$ & $14.0 \pm 5.1$ & $17.1 \pm 10.4$ & 0.50 \\
\hline \multicolumn{6}{|l|}{ Medication $(n, \%)$} \\
\hline Insulin & 0 & $8(34.8)$ & $8(61.5)$ & $10(71.4)$ & 0.09 \\
\hline Metformin & 0 & $15(65.2)$ & $7(53.8)$ & $7(50)$ & 0.62 \\
\hline Statin & 0 & $16(69.6)$ & $8(61.5)$ & $6(42.9)$ & 0.32 \\
\hline Fibrate & 0 & $1(4.3)$ & $1(7.7)$ & $0(0)$ & 0.59 \\
\hline Sartane & 0 & $15(65.2)$ & $7(53.8)$ & $10(71.4)$ & 0.59 \\
\hline
\end{tabular}

DR: diabetic retinopathy; $n$ : sample size; PDR: proliferative diabetic retinopathy; SD: standard deviation; F: females. ${ }^{*}$ Significant difference between healthy controls and all three of the DR groups.

TABle 2: Concentrations (mean \pm SD; pg/ml) of TGF- $\beta 1$, TGF- $\beta 2$, and TGF- $\beta 3$ in serum and AH of healthy individuals (controls) and diabetic patients with different stages of DR. The fold change for each group was calculated relative to the control group.

\begin{tabular}{|c|c|c|c|c|c|c|c|}
\hline & \multirow{2}{*}{$\begin{array}{l}\text { Healthy controls } \\
\text { Mean } \pm \text { SD } \\
(\mathrm{pg} / \mathrm{ml})\end{array}$} & \multicolumn{2}{|c|}{ Non-apparent DR } & \multicolumn{2}{|c|}{ Mild/moderate NPDR } & \multicolumn{2}{|c|}{ Advanced NPDR/PDR } \\
\hline & & $\begin{array}{l}\text { Mean } \pm \text { SD } \\
\quad(\mathrm{pg} / \mathrm{ml})\end{array}$ & $\begin{array}{l}\text { Relative } \\
\text { change }^{*}\end{array}$ & $\begin{array}{l}\text { Mean } \pm \text { SD } \\
\quad(\mathrm{pg} / \mathrm{ml})\end{array}$ & $\begin{array}{l}\text { Relative } \\
\text { change* }\end{array}$ & $\begin{array}{l}\text { Mean } \pm \text { SD } \\
\quad(\mathrm{pg} / \mathrm{ml})\end{array}$ & $\begin{array}{l}\text { Relative } \\
\text { change* }\end{array}$ \\
\hline \multicolumn{8}{|c|}{ TGF- $\beta 1$} \\
\hline Serum & $31,445 \pm 16,231$ & $46,825 \pm 15,812$ & 1.5 & $30,571 \pm 18,709$ & 1.0 & $25,267 \pm 15,082$ & 0.8 \\
\hline $\mathrm{AH}$ & $137 \pm 129$ & $196 \pm 230$ & 1.4 & $361 \pm 320$ & 2.6 & $761 \pm 450$ & 5.5 \\
\hline \multicolumn{8}{|l|}{ TGF- $\beta 2$} \\
\hline Serum & $1,747 \pm 340$ & $1,785 \pm 243$ & 1.0 & $1,687 \pm 328$ & 1.0 & $1,553 \pm 404$ & 0.9 \\
\hline $\mathrm{AH}$ & $19,216 \pm 11,105$ & $14,844 \pm 12,607$ & 0.8 & $24,627 \pm 19,266$ & 1.3 & $32,398 \pm 15,395$ & 1.7 \\
\hline \multicolumn{8}{|c|}{ TGF- $\beta 3$} \\
\hline Serum & $1,578 \pm 536$ & $1,882 \pm 433$ & 1.2 & $1,524 \pm 650$ & 1.0 & $1,273 \pm 603$ & 0.8 \\
\hline $\mathrm{AH}$ & $27 \pm 19$ & $38 \pm 36$ & 1.4 & $49 \pm 34$ & 1.8 & $103 \pm 66$ & 3.8 \\
\hline
\end{tabular}

${ }^{*}$ Factor of change compared to healthy controls.

variables measured at a nominal level. A $p<0.05$ was considered to be significant. To control the risk of introducing type I error as a result of multiple comparisons, we applied the Holm correction, which progressively adapts the threshold for rejecting the null hypothesis. The statistical analyses were performed using the open-source software R (version 3.3.2 2016 RStudio, Inc.; psych package) and SPSS (version 23.0; IBM SPSS Statistics, Armonk, NY, USA). Results are expressed as the mean \pm standard deviation $(\mathrm{SD}) \quad(\mathrm{pg} / \mathrm{ml})$ unless stated otherwise.

Since the majority of the target proteins in the $\mathrm{AH}$ were expected to range at the lower limit of the test system, we decided to use the absolute concentration values for statistical comparison, whereas the relative change of the targets between the three DR groups was compared to the healthy controls. These and the number of measurements ranging below the LLOQ were used for interpretation of their biological meaning.

\section{Results}

3.1. Demographic and Clinical Characteristics of the Study Population. Paired samples from a total of 67 eyes $(67$ patients) were included: healthy controls $(n=17)$, nonapparent DR $(n=23)$, mild/moderate NPDR $(n=13)$, and advanced NPDR/PDR $(n=14)$. The demographic characteristics of the patients are displayed in Table 1.

3.2. Serum and AH Concentrations of TGF- $\beta$ Isoforms. The concentrations of TGF- $\beta$ isoforms in the serum and $\mathrm{AH}$ throughout the different stages of DR are displayed in Table 2 and Figure 1. The mean \pm SD concentrations and the relative changes for each group compared to the controls are presented in Table 2 . Levels of TGF- $\beta 1$ in serum were comparable between controls and all stages of retinal disease (Table 3, Figure 1), and no relevant differences in proportions were observed in the DR groups relative to the controls (Table 2). Patients with non-apparent DR showed higher levels of TGF- $\beta 1$ compared to healthy controls and patients with advanced NPDR/PDR. However, these differences were no longer significant after the Holm correction. In the $\mathrm{AH}$, on the other hand, we observed a stepwise increase of the TGF- $\beta 1$ concentrations with increasing severity of DR compared to the controls (Table 2). There was a significant difference in concentrations between healthy controls and patients 


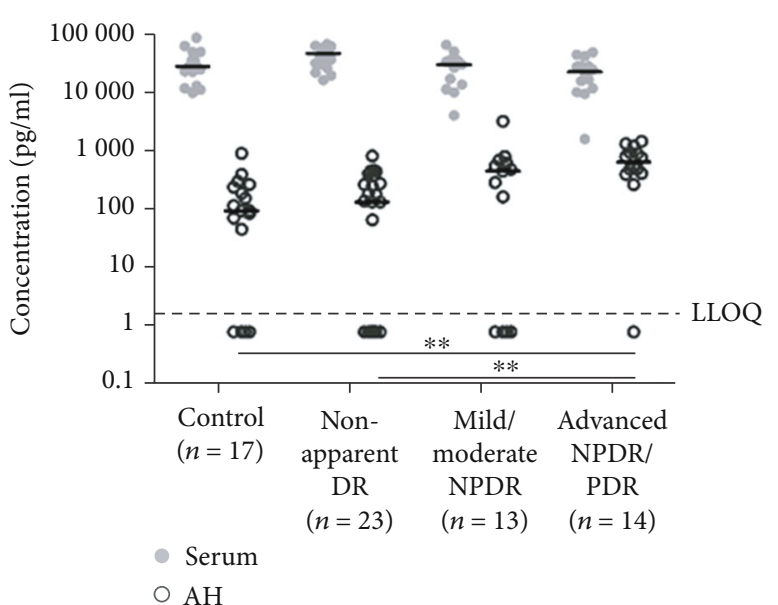

(a)

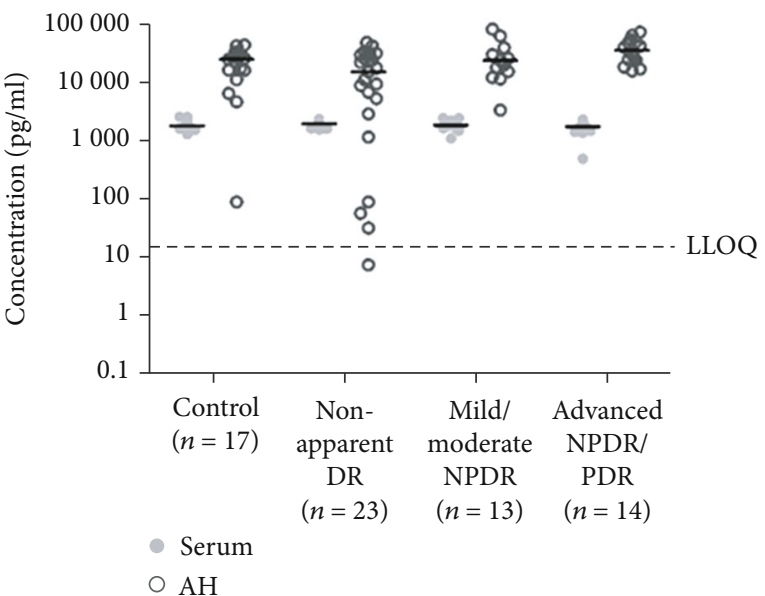

(b)

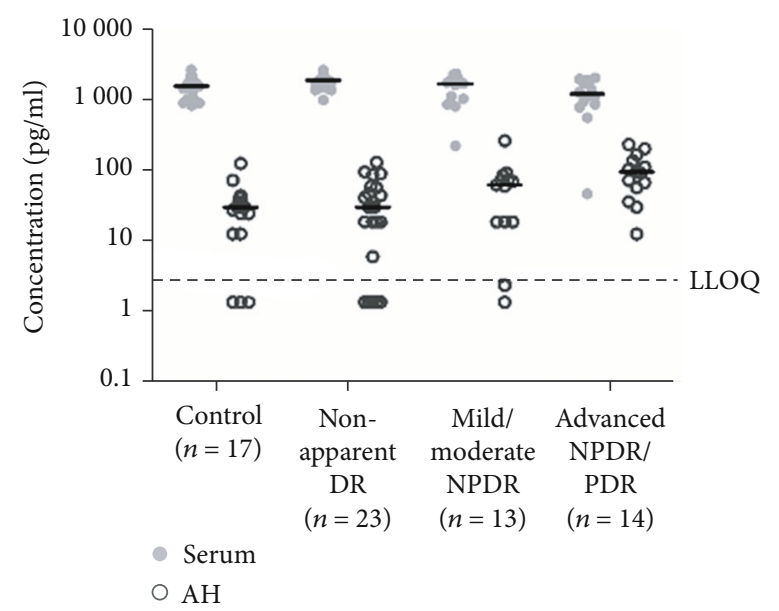

(c)

FIgURe 1: Scatter plots (log scale pg/ml) showing the concentrations of TGF- $\beta 1$ (a), TGF- $\beta 2$ (b), and TGF- $\beta 3$ (c) in serum and AH throughout the different stages of DR. The values below the LLOQ were replaced with half the value of the LLOQ. Black lines represent the median value for each group. The dotted line shows the LLOQ of the assay for each protein. ${ }^{* *} p<0.01$.

with advanced NPDR/PDR (where the relative change from healthy controls to patients with advanced NPDR/PDR was 5.5 -fold). In addition, a significant difference between patients with non-apparent DR and advanced NPDR/PDR was found (Table 3 ).

Whereas all serum samples showed TGF- $\beta 1$ concentrations above the LLOQ, these were generally low in the AH and ranged below the LLOQ in several samples, including the control group $(4 / 17,24 \%)$, non-apparent DR group (9/23, 39\%), mild/moderate NPDR group $(4 / 13,31 \%)$, and advanced NPDR/PDR group $(1 / 14,7 \%)$. There was no difference between the groups regarding the number of concentrations below the LLOQ, neither for the AH nor for the serum in any of the TGF- $\beta$ isoforms (chi-squared test of independence, $p>0.05$ ).

Serum and AH TGF- $\beta 2$ concentrations were comparable between the controls and the different DR severity groups (Table 3, Figure 1), with the exception of an increase in TGF- $\beta 2$ levels in the AH between the non-apparent DR and advanced NPDR/PDR groups $(p=0.011)$, which did not remain significant after applying the Holm correction.
No relevant differences in proportions were observed in the DR groups relative to the control group for TGF- $\beta 2$ (Table 2). All serum samples showed concentrations above the LLOQ, and only one AH sample presented with concentrations below the LLOQ (non-apparent DR $(1 / 23,4 \%)$ ).

Serum levels of TGF- $\beta 3$ were comparable between the control group and the different DR groups. Similar to TGF$\beta 1$, the AH TGF- $\beta 3$ levels increased with the progression of DR (Table 2), resulting in a 1.8 -fold increase in the concentration of TGF- $\beta 3$ in patients with mild/moderate NPDR and a 3.8-fold increase in patients with advanced NPDR/PDR compared to the controls. However, these differences did not remain significant after the Holm correction. No serum samples showed concentrations below the LLOQ. The number of values below the LLOQ in the AH for each group was as follows: control group $(3 / 17,18 \%)$, nonapparent DR $(5 / 23,22 \%)$, and mild/moderate NPDR (2/13, $15 \%)$ (chi-squared test of independence, $p>0.05$ ).

3.3. Serum and AH Concentrations of MMP-3, MMP-9, and TIMP-1. The serum and AH concentrations of MMP-3, 
TABLE 3: Comparison of concentrations of TGF- $\beta 1$, TGF- $\beta 2$, and TGF- $\beta 3$ in serum and AH of healthy individuals (controls) and diabetic patients with different stages of DR.

\begin{tabular}{|c|c|c|c|c|c|c|}
\hline & 1 vs. 2 & 1 vs. 3 & 1 vs. 4 & 2 vs. 3 & 2 vs. 4 & 3 vs. 4 \\
\hline \multicolumn{7}{|l|}{ TGF- $\beta 1$} \\
\hline Serum & $p=0.024$ & & & $p=0.027$ & $p=0.0019$ & \\
\hline $\mathrm{AH}$ & & & $p=0.00036$ & & $p=0.00036$ & \\
\hline \multicolumn{7}{|l|}{ TGF- $\beta 2$} \\
\hline \multicolumn{7}{|l|}{ Serum } \\
\hline $\mathrm{AH}$ & & & & & $p=0.011$ & \\
\hline \multicolumn{7}{|l|}{ TGF- $\beta 3$} \\
\hline Serum & & & & & $p=0.023$ & \\
\hline $\mathrm{AH}$ & & & $p=0.0019$ & & $p=0.0033$ & \\
\hline
\end{tabular}

1: healthy controls; 2: non-apparent DR; 3: mild/moderate NPDR; 4: advanced NPDR/PDR. Significant results after the Holm correction are displayed in bold.

TABLE 4: Concentrations (mean \pm SD; pg/ml) of MMP-3, MMP-9, and TIMP-1 in serum and AH of healthy individuals (controls) and diabetic patients with different stages of DR. The fold change for each group was calculated relative to the control group.

\begin{tabular}{|c|c|c|c|c|c|c|c|}
\hline & \multirow{2}{*}{$\begin{array}{l}\text { Healthy controls } \\
\text { Mean } \pm \text { SD } \\
(\mathrm{pg} / \mathrm{ml})\end{array}$} & \multicolumn{2}{|c|}{ Non-apparent DR } & \multicolumn{2}{|c|}{ Mild/moderate NPDR } & \multicolumn{2}{|c|}{ Advanced NPDR/PDR } \\
\hline & & $\begin{array}{l}\text { Mean } \pm \text { SD } \\
(\mathrm{pg} / \mathrm{ml})\end{array}$ & $\begin{array}{l}\text { Relative } \\
\text { change }^{*}\end{array}$ & $\begin{array}{l}\text { Mean } \pm \text { SD } \\
(\mathrm{pg} / \mathrm{ml})\end{array}$ & $\begin{array}{l}\text { Relative } \\
\text { change* }\end{array}$ & $\begin{array}{l}\text { Mean } \pm \text { SD } \\
(\mathrm{pg} / \mathrm{ml})\end{array}$ & $\begin{array}{l}\text { Relative } \\
\text { change* }\end{array}$ \\
\hline \multicolumn{8}{|c|}{ MMP-3 } \\
\hline Serum & $510 \pm 457$ & $762 \pm 682$ & 1.5 & $1,044 \pm 1,254$ & 2.0 & $1,187 \pm 599$ & 2.3 \\
\hline $\mathrm{AH}$ & $131 \pm 67$ & $231 \pm 123$ & 1.8 & $647 \pm 602$ & 5.0 & $1,008 \pm 791$ & 7.7 \\
\hline \multicolumn{8}{|l|}{ MMP-9 } \\
\hline Serum & $5,457 \pm 2,518$ & $9,137 \pm 6,153$ & 1.7 & $10,696 \pm 8,062$ & 2.0 & $12,266 \pm 10,747$ & 2.2 \\
\hline $\mathrm{AH}$ & $12 \pm 5$ & $11 \pm 7$ & 0.9 & $15 \pm 8$ & 1.3 & $29 \pm 24$ & 2.3 \\
\hline \multicolumn{8}{|l|}{ TIMP-1 } \\
\hline Serum & $188,378 \pm 60,029$ & $205,462 \pm 78,693$ & 1.1 & $176,173 \pm 53,489$ & 0.9 & $245,471 \pm 66,851$ & 1.3 \\
\hline $\mathrm{AH}$ & $172,552 \pm 55,975$ & $141,695 \pm 54,074$ & 0.8 & $191,046 \pm 59,229$ & 1.1 & $415,028 \pm 153,150$ & 2.4 \\
\hline
\end{tabular}

${ }^{*}$ Factor of change compared to healthy controls.

MMP-9, and TIMP-1 throughout the different stages of DR are presented in Table 4 and Figure 2.

The relative and absolute levels of MMP-3 tended to increase in the serum and $\mathrm{AH}$ with the advancement of $\mathrm{DR}$ compared to the controls (Table 4). In the serum, there was no significant difference in concentrations of MMP-3 between the groups. In the $\mathrm{AH}$, we did, however, find a significant difference in the concentrations of MMP-3 between healthy controls and patients with advanced NPDR/PDR (where the relative change from healthy controls to patients with advanced NPDR/PDR was 7.7-fold), as well as a significant increase between the patients with non-apparent DR and advanced NPDR/PDR (Table 5).

All serum and AH concentrations ranged above the LLOQ, except for three values in the serum (control group $(2 / 17,12 \%)$ and mild/moderate NPDR $(1 / 13,8 \%))$ and two values in the $\mathrm{AH}$ (control group $(1 / 17,6 \%)$ and non-apparent DR $(1 / 23$, $4 \%)$ ). There was no difference between the groups regarding the number of concentrations below the LLOQ, neither for the $\mathrm{AH}$ nor for the serum in any of the MMPs or TIMP-1 (chi-squared test of independence, $p>0.05$ ).

Serum concentration levels of MMP-9 were similar between the groups (Table 5), whereas the concentrations of MMP-9 in the AH tended to increase in the advanced stages of the disease, with a 2.3-fold increase in the advanced NPDR/PDR group relative to the control group. However, the difference between the control group and the advanced NPDR/PDR group did not remain significant after the Holm correction. No relevant differences in proportions were observed in the DR groups relative to the control group (Table 4). All serum and AH samples showed MMP-9 concentrations above the LLOQ. Again, there was no difference between the groups regarding the number of target concentrations above the LLOQ (chi-squared test of independence, $p=0.52)$.

Serum concentrations and proportions of TIMP-1 were similar in the healthy controls and the different DR stages (Tables 4 and 5, Figure 2), whereas a significant increase in TIMP-1 concentrations was observed in the later stages of DR (Table 5). All serum and AH samples showed detectable concentrations of TIMP-1.

\section{Discussion}

We were able to demonstrate an increase of TGF- $\beta 1$, MMP3 , and TIMP-1 in the AH in the later stages of DR, whereas 


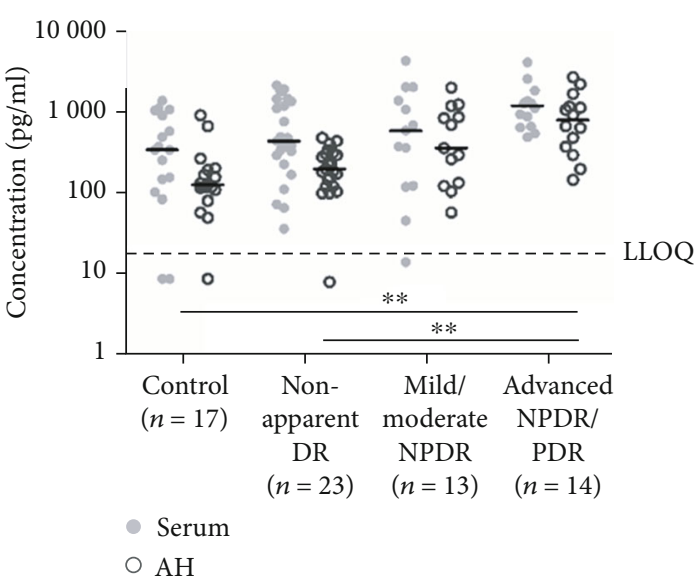

(a)

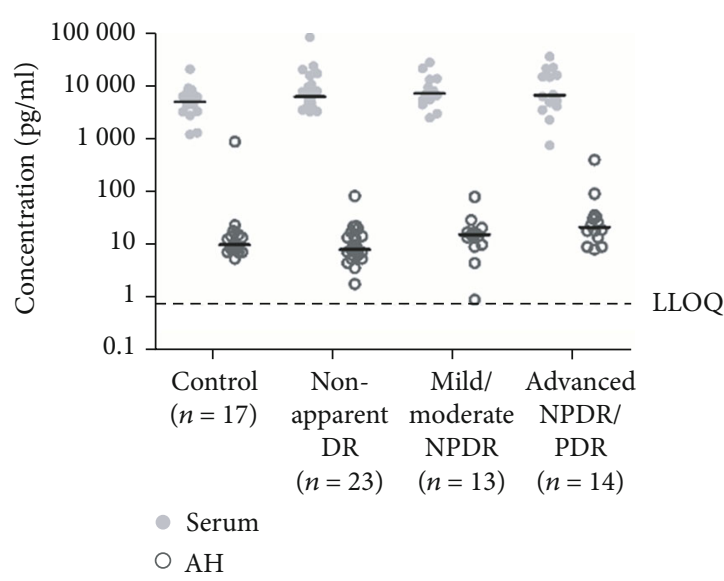

(b)

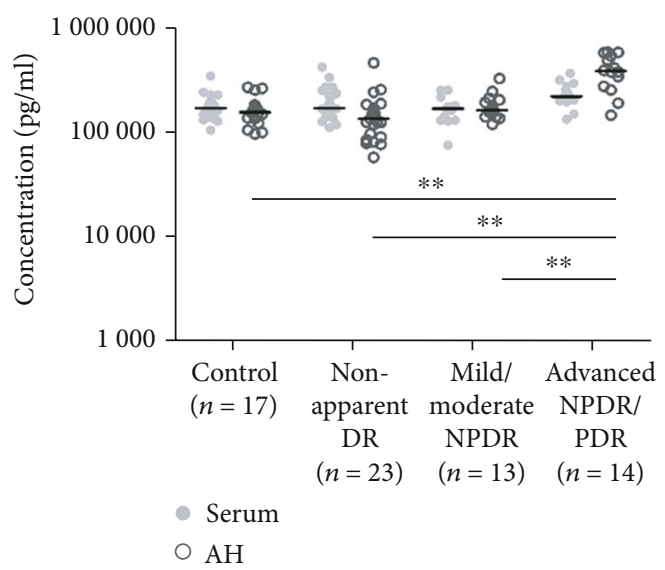

(c)

FIGURE 2: Scatter plots (log scale pg/ml) showing the concentrations of MMP-3 (a), MMP-9 (b), and TIMP-1 (c) in serum and AH throughout the different stages of DR. The values below the LLOQ were replaced with half the value of the LLOQ. Black lines represent the median value for each group. The dotted line shows the LLOQ of the assay for each protein. ${ }^{* *} p<0.01$.

TABLE 5: Comparison of concentrations of MMP-3, MMP-9, and TIMP-1 in serum and AH of healthy individuals (controls) and diabetic patients with different stages of DR.

\begin{tabular}{|c|c|c|c|c|c|c|}
\hline & 1 vs. 2 & 1 vs. 3 & 1 vs. 4 & 2 vs. 3 & 2 vs. 4 & 3 vs. 4 \\
\hline \multicolumn{7}{|l|}{ MMP-3 } \\
\hline Serum & & & 0.013 & & & \\
\hline $\mathrm{AH}$ & $p=0.014$ & $p=0.011$ & $p<0.0001$ & & $p=0.0004$ & \\
\hline \multicolumn{7}{|l|}{ MMP-9 } \\
\hline \multicolumn{7}{|l|}{ Serum } \\
\hline $\mathrm{AH}$ & & & $p=0.011$ & & $p=0.0041$ & \\
\hline \multicolumn{7}{|l|}{ TIMP-1 } \\
\hline Serum & & & $p=0.027$ & & & $p=0.027$ \\
\hline $\mathrm{AH}$ & & & $p<0.0001$ & $p=0.014$ & $p<0.0001$ & $p=0.0002$ \\
\hline
\end{tabular}

1: healthy controls; 2: non-apparent DR; 3: mild/moderate NPDR; 4: advanced NPDR/PDR. Significant results after the Holm correction are displayed in bold.

no changes in concentrations were found in the serum with the progression of DR. Thus, the development and progression of DR seems to comprise a local regulatory process within the eye that is independent of systemic disease. Our results are in alignment with previous studies showing that biological changes to the intraocular environment are already detectable before the first clinical signs of DR develop, and these increase with the severity of DR [32-34]. The stagespecific increase of these biomarkers, although not strong enough to support a central role of these cytokines for DR, confirms their involvement in the pathogenesis of the disease and may explain the observed basal membrane thickening 
[35]. These results might suggest a potential use of these proteins as biomarkers of diabetic retinopathy. However, their use as potential targets in drug therapy development needs to be evaluated using animal models.

Under physiological or healthy conditions, as in our control group, TGF- $\beta 2$ is the most abundant and the only TGF- $\beta$ isoform that is present in a higher concentration in the $\mathrm{AH}$ than in the serum, which is in line with previous reports [36]. Since we did not find changes in its concentration with the advancement of retinal disease, TGF- $\beta 2$ likely plays a subordinate role in the pathogenesis of DR. This result, however, also highlights the importance of measuring TGF- $\beta$ isoforms separately, since high concentrations of TGF- $\beta 2$ may by far outweigh (even relevant) changes in the expression of the less abundant TGF- $\beta 1$ and TGF- $\beta 3$.

TGF- $\beta$ is known to play a fundamental role in vascular quiescence, pericyte recruitment, and angiogenesis $[9,37$, 38]. Serum concentrations of TGF- $\beta 1$ in our series tended to be higher in diabetics without apparent DR compared to healthy controls, whereas lower concentrations were observed in the advanced NPDR/PDR stage. In line with these findings, higher serum TGF- $\beta 1$ levels in patients with type 1 DM with NPDR compared to those without microvascular complications and healthy controls have been reported [39]. Conclusive clinical evidence, however, has not been established since different studies in type $1 \mathrm{DM}$ reported heterogeneous results, with a tendency towards an increase in TGF- $\beta$ serum levels with the duration of diabetes and its microvascular complications $[40,41]$.

While we found no difference in serum MMP-3, MMP-9, and TIMP-1 concentrations between the DR stages, we observed a pronounced upregulation of MMP-3 in the AH in mild/moderate NPDR and advanced NPDR/PDR, as well as an upregulation of TIMP-1 during the late stage of DR. These results are in line with previous studies that have reported elevated levels of TIMP-1 in VF in PDR [42, 43]. MMP-9 concentrations tended to increase in the advanced stages of the disease, although this significance was lost after the application of the Holm correction. Roles for both MMP2 and MMP-9 in the later stages of DR have been expected [44, 45], and an increase in MMP-9 concentrations in the $\mathrm{AH}$ and $\mathrm{VF}$ was reported in the late stages of the disease $[46,47]$. However, our results suggest that MMP-3 and TIMP-1 or the balance between MMP-9 and TIMP-1 may play a more predominant role already early in the pathogenesis of DR [48].

Studies in animal models demonstrated that MMP-3 is expressed in Müller cells in the retina of adult mice $[49,50]$ and predominantly in the ganglion cell layer (GCL) and inner nuclear layer (INL) neurons in the retina of adult rats $[51,52]$. A pathological or beneficial role of MMP-3 in the retina has been described for several diseases based on animal models [50-53]. A local source for this enzyme fits well with the stronger correlation of AH compared to serum MMP-3 with advanced DR. However, whether MMP-3 has a causative or protective role in the pathogenesis of $\mathrm{DR}$ remains to be determined.

Whereas several studies compared $\mathrm{AH}$ and serum concentrations of different cytokines in DR and control groups
$[54,55]$, only a few studies have attempted to correlate specific biomarkers to the severity of DR $[56,57]$. Although currently there exists no clear concept as to the regulation of the retinal environment and the source of the local cytokinome, available evidence seems in favor of local rather than systemic factors driving the pathogenesis and progression of both DR and DME [55]. This would explain that the AH, but not serum, concentrations of TGF- $\beta 1$, MMP-3, and TIMP-1 in our series changed with the severity of DR. However, brain-derived neurotrophic factor levels in the serum were reported to correlate more closely with the severity of $\mathrm{DR}$ than the corresponding $\mathrm{AH}$ levels [58], indicating that this cannot readily be generalized.

The strengths of this study include a well-defined DR severity in all cases, a relatively large sample size, the parallel workup of the serum and $\mathrm{AH}$, and the exclusion of eyes with a history of recent vitreal hemorrhage, intravitreal treatment, or panretinal laser photocoagulation within 6 months of surgery. Its retrospective nature and the limited test system sensitivity may limit the understanding of cytokine concentrations in the context of the pathophysiological concept of this disease. Multiple bead assay systems generally lack the sensitivity of specific single-target ELISA. Therefore, the absolute concentrations of cytokines vary depending on the multiple bead assay system in use and cannot directly be compared between different studies. In an attempt to compensate for this limitation, we decided to not only report the absolute biomarker concentrations but also interpret the factor of change for each target between the different DR severity groups and the healthy controls. This approach could also provide an option to allow for comparison between different studies and differentiation between statistically significant and/or clinically relevant changes.

The demographic and clinical characteristics of the disease groups were similar and showed no differences, whereas the control group presented a different gender ratio. A statistical analysis for the studied proteins was carried out in the non-apparent diabetic retinopathy group, and no significant differences were observed between genders, indicating that the possibility of this bias to affect the outcomes and conclusions seems unlikely.

With the aim of identifying stage-specific differences in the concentrations of the targets in the early and late stages of the disease, the groups mild and moderate NPDR (early DR) and advanced NPDR and PDR (late DR) had to be merged in order to achieve sufficient statistical power for this analysis. The rigid case selection criteria applied here, on the other hand, may be a strength, outbalancing this grouping strategy. This, namely, affects the exclusion of patients in the advanced NPDR/PDR with vitreous hemorrhage and intravitreal treatment within the past 6 months, as antiVEGF treatment can affect the levels of cytokines [59]. All except 3 patients $(3 / 14,21 \%)$ included in this group had received panretinal photocoagulation at some point, and only 4 patients $(4 / 14,29 \%)$ presented DME. An exploratory analysis revealed no differences in the studied targets between patients with and without panretinal photocoagulation and patients with and without DME (data not shown). This lack of difference is in agreement with a preclinical study 
which found no significant differences in TGF- $\beta 2$ in the AH of rats after panretinal photocoagulation treatment [60].

\section{Conclusion}

In conclusion, we found that the concentrations of TGF- $\beta 1$, MMP-3, and TIMP-1 in the aqueous humor, but not in the serum, are upregulated with the progression of DR, suggesting their contribution to the local regulation of DR.

\section{Data Availability}

The data obtained in this study is available from the corresponding author upon request.

\section{Conflicts of Interest}

The authors declare that there is no conflict of interest regarding the publication of this paper. JGG acts as an advisor for several pharmaceutical companies (AbbVie, Alcon, Roche, Bayer, and Novartis) and participates in several international industry-sponsored clinical studies. These activities had no bearing on the study that gave rise to the submitted article, for which JGG received neither direct nor indirect financial support, nor has he conflicts of interest with any of the presented data or this work.

\section{Acknowledgments}

The authors would like to acknowledge Alain Despoint and Robert Rieben for conducting the Bio-Plex assay and for their support during the development of this work. We are very grateful to the Foundation Lindenhof Bern for the generous support (study identifier 17-05-F) that made this study possible.

\section{References}

[1] American Academy of Ophthalmology Retina/Vitreous Panel, Preferred practice pattern guidelines. Diabetic retinopathy, American Academy of Ophthalmology, San Francisco, CA, 2016.

[2] International Diabetes Federation, IDF Diabetes Atlas, International Diabetes Federation, Brussels, Belgium, 9th edition, 2019.

[3] J. W. Yau, S. L. Rogers, R. Kawasaki et al., "Global prevalence and major risk factors of diabetic retinopathy," Diabetes Care, vol. 35, no. 3, pp. 556-564, 2012.

[4] D. S. Fong, L. Aiello, T. W. Gardner et al., "Retinopathy in diabetes," Diabetes Care, vol. 27, Supplement 1, pp. S84-S87, 2004.

[5] M. Lodyga and B. Hinz, "TGF- $\beta 1$ - a truly transforming growth factor in fibrosis and immunity," Seminars in Cell \& Developmental Biology, vol. 101, pp. 123-139, 2020.

[6] T. Huang, S. L. Schor, and A. P. Hinck, "Biological activity differences between TGF- $\beta 1$ and TGF- $\beta 3$ correlate with differences in the rigidity and arrangement of their component monomers," Biochemistry, vol. 53, no. 36, pp. 5737-5749, 2014.
[7] G. Proetzel, S. A. Pawlowski, M. V. Wiles et al., "Transforming growth factor- $\beta 3$ is required for secondary palate fusion," Nature Genetics, vol. 11, no. 4, pp. 409-414, 1995.

[8] L. P. Sanford, I. Ormsby, A. C. Gittenberger-de Groot et al., "TGFbeta2 knockout mice have multiple developmental defects that are non-overlapping with other TGFbeta knockout phenotypes," Development, vol. 124, no. 13, pp. 26592670, 1997.

[9] J. F. Arboleda-Velasquez, C. N. Valdez, C. K. Marko, and P. A. D'Amore, "From pathobiology to the targeting of pericytes for the treatment of diabetic retinopathy," Current Diabetes Reports, vol. 15, no. 2, p. 573, 2015.

[10] C. Gerhardinger, Z. Dagher, P. Sebastiani, Y. S. Park, and M. Lorenzi, "The transforming growth factor- $\beta$ pathway is a common target of drugs that prevent experimental diabetic retinopathy," Diabetes, vol. 58, no. 7, pp. 1659-1667, 2009.

[11] R. J. Van Geest, I. Klaassen, I. M. Vogels, C. J. Van Noorden, and R. O. Schlingemann, "Differential TGF- $\beta$ signaling in retinal vascular cells: a role in diabetic retinopathy?," Investigative Ophthalmology \& Visual Science, vol. 51, no. 4, pp. 1857-1865, 2010.

[12] W. Shen, S. Li, S. H. Chung et al., "Tyrosine phosphorylation of VE-cadherin and claudin-5 is associated with TGF- $\beta 1$ induced permeability of centrally derived vascular endothelium," European Journal of Cell Biology, vol. 90, no. 4, pp. 323-332, 2011.

[13] T. E. Walshe, M. Saint-Geniez, A. S. Maharaj, E. Sekiyama, A. E. Maldonado, and P. A. D'Amore, "TGF- $\beta$ is required for vascular barrier function, endothelial survival and homeostasis of the adult microvasculature," PLoS One, vol. 4, no. 4, article e5149, 2009.

[14] B. M. Braunger, S. V. Leimbeck, A. Schlecht, C. Volz, H. Jägle, and E. R. Tamm, "Deletion of ocular transforming growth factor $\beta$ signaling mimics essential characteristics of diabetic retinopathy," The American Journal of Pathology, vol. 185, no. 6, pp. 1749-1768, 2015.

[15] J. Drankowska, M. Kos, A. Kościuk et al., "MMP targeting in the battle for vision: recent developments and future prospects in the treatment of diabetic retinopathy," Life Sciences, vol. 229, pp. 149-156, 2019.

[16] C. Amălinei, I. D. Căruntu, and R. A. Bălan, "Biology of metalloproteinases," Romanian Journal of Morphology and Embryology, vol. 48, no. 4, pp. 323-334, 2007.

[17] S. J. Giebel, G. Menicucci, P. G. McGuire, and A. Das, "Matrix metalloproteinases in early diabetic retinopathy and their role in alteration of the blood-retinal barrier," Laboratory Investigation, vol. 85, no. 5, pp. 597-607, 2005.

[18] J. Kim, C. S. Kim, Y. M. Lee, K. Jo, S. D. Shin, and J. S. Kim, "Methylglyoxal induces hyperpermeability of the bloodretinal barrier via the loss of tight junction proteins and the activation of matrix metalloproteinases," Graefe's Archive for Clinical and Experimental Ophthalmology, vol. 250, no. 5, pp. 691-697, 2012.

[19] M. A. Behzadian, X. L. Wang, L. J. Windsor, N. Ghaly, and R. B. Caldwell, "TGF- $\beta$ increases retinal endothelial cell permeability by increasing MMP-9: possible role of glial cells in endothelial barrier function," Investigative Ophthalmology \& Visual Science, vol. 42, no. 3, pp. 853-859, 2001.

[20] Q. Yu and I. Stamenkovic, "Cell surface-localized matrix metalloproteinase-9 proteolytically activates TGF-beta and promotes tumor invasion and angiogenesis," Genes \& Development, vol. 14, no. 2, pp. 163-176, 2000. 
[21] Y. Chen, W. Wang, F. Liu, L. Tang, R. Tang, and W. Li, “Apoptotic effect of mtrix metalloproteinases 9 in the development of diabetic retinopathy," International Journal of Clinical and Experimental Pathology, vol. 8, no. 9, pp. 10452-10459, 2015.

[22] R. A. Kowluru, G. Mohammad, J. M. dos Santos, and Q. Zhong, "Abrogation of MMP-9 gene protects against the development of retinopathy in diabetic mice by preventing mitochondrial damage," Diabetes, vol. 60, no. 11, pp. 30233033, 2011.

[23] D. Navaratna, P. G. McGuire, G. Menicucci, and A. Das, "Proteolytic degradation of VE-cadherin alters the blood-retinal barrier in diabetes," Diabetes, vol. 56, no. 9, pp. 2380-2387, 2007.

[24] R. A. Kowluru, Q. Zhong, and J. M. Santos, "Matrix metalloproteinases in diabetic retinopathy: potential role of MMP9," Expert Opinion on Investigational Drugs, vol. 21, no. 6, pp. 797-805, 2012.

[25] G. A. Rosenberg, "Matrix metalloproteinases in neuroinflammation," Glia, vol. 39, no. 3, pp. 279-291, 2002.

[26] N. Cui, M. Hu, and R. A. Khalil, "Biochemical and biological attributes of matrix metalloproteinases," Progress in Molecular Biology and Translational Science, vol. 147, pp. 1-73, 2017.

[27] K. J. Gurney, E. Y. Estrada, and G. A. Rosenberg, "Blood-brain barrier disruption by stromelysin-1 facilitates neutrophil infiltration in neuroinflammation," Neurobiology of Disease, vol. 23, no. 1, pp. 87-96, 2006.

[28] A. M. Lech, G. Wiera, and J. W. Mozrzymas, "Matrix metalloproteinase-3 in brain physiology and neurodegeneration," Advances in Clinical and Experimental Medicine, vol. 28, no. 12, pp. 1717-1722, 2019.

[29] C. P. Wilkinson, F. L. Ferris 3rd, R. E. Klein et al., "Proposed international clinical diabetic retinopathy and diabetic macular edema disease severity scales," Ophthalmology, vol. 110, no. 9, pp. 1677-1682, 2003.

[30] S. Zandi, C. Tappeiner, I. B. Pfister, A. Despont, R. Rieben, and J. G. Garweg, "Vitreal cytokine profile differences between eyes with epiretinal membranes or macular holes," Investigative Ophthalmology \& Visual Science, vol. 57, no. 14, pp. 63206326, 2016.

[31] I. B. Pfister, S. Zandi, C. Gerhardt, J. Spindler, N. Reichen, and J. G. Garweg, "Risks and challenges in interpreting simultaneous analyses of multiple cytokines," Translational Vision Science \& Technology, vol. 9, no. 7, p. 27, 2020.

[32] C. M. Cheung, M. Vania, M. Ang, S. P. Chee, and J. Li, "Comparison of aqueous humor cytokine and chemokine levels in diabetic patients with and without retinopathy," Molecular Vision, vol. 18, pp. 830-837, 2012.

[33] A. M. Valverde, S. Miranda, M. García-Ramírez, Á. González-Rodriguez, C. Hernández, and R. Simó, "Proapoptotic and survival signaling in the neuroretina at early stages of diabetic retinopathy," Molecular Vision, vol. 19, pp. 47-53, 2013.

[34] N. Dong, B. Xu, B. Wang, and L. Chu, "Study of 27 aqueous humor cytokines in patients with type 2 diabetes with or without retinopathy," Molecular Vision, vol. 19, pp. 1734-1746, 2013.

[35] S. Roy and D. Kim, "Retinal capillary basement membrane thickening: role in the pathogenesis of diabetic retinopathy," Progress in Retinal and Eye Research, vol. 100903, 2020.

[36] S. Saika, "TGF_ $\beta_{-}$pathobiology in the eye," Laboratory Investigation, vol. 86, no. 2, pp. 106-115, 2006.
[37] N. Warmke, K. J. Griffin, and R. M. Cubbon, "Pericytes in diabetes-associated vascular disease," Journal of Diabetes and its Complications, vol. 30, no. 8, pp. 1643-1650, 2016.

[38] Z. Dagher, C. Gerhardinger, J. Vaz, M. Goodridge, F. Tecilazich, and M. Lorenzi, "The increased transforming growth factor- $\beta$ signaling induced by diabetes protects retinal vessels," The American Journal of Pathology, vol. 187, no. 3, pp. 627-638, 2017.

[39] K. Zorena, E. Malinowska, D. Raczyńska, M. Myśliwiec, and K. Raczyńska, "Serum concentrations of transforming growth factor-beta 1 in predicting the occurrence of diabetic retinopathy in juvenile patients with type 1 diabetes mellitus," Journal Diabetes Research, vol. 2013, article 614908, 6 pages, 2013.

[40] Y. C. Qiao, J. Shen, L. He et al., "Changes of regulatory T cells and of proinflammatory and immunosuppressive cytokines in patients with type 2 diabetes mellitus: a systematic review and meta-analysis," Journal Diabetes Research, vol. 2016, article 3694957, 19 pages, 2016.

[41] K. Zorena, D. Raczyńska, P. Wiśniewski et al., "Relationship between Serum Transforming Growth Factor $\beta 1$ Concentrations and the Duration of Type 1 Diabetes Mellitus in Children and Adolescents," Mediators of Inflammation, vol. 2013, Article ID 849457, 6 pages, 2013.

[42] R. J. van Geest, I. Klaassen, S. Y. Lesnik-Oberstein et al., "Vitreous TIMP-1 levels associate with neovascularization and TGF- $\beta 2$ levels but not with fibrosis in the clinical course of proliferative diabetic retinopathy," Journal of Cell Communication and Signaling, vol. 7, no. 1, pp. 1-9, 2013.

[43] A. M. Abu el-Asrar, A. Ahmad, E. Bittoun et al., "Differential expression and localization of human tissue inhibitors of metalloproteinases in proliferative diabetic retinopathy," Acta Ophthalmologica, vol. 96, no. 1, pp. e27-e37, 2018.

[44] R. A. Kowluru, "Mitochondrial stability in diabetic retinopathy: lessons learned from epigenetics," Diabetes, vol. 68, no. 2, pp. 241-247, 2019.

[45] K. Jayashree, M. Yasir, G. P. Senthilkumar, K. Ramesh Babu, V. Mehalingam, and P. S. Mohanraj, "Circulating matrix modulators (MMP-9 and TIMP-1) and their association with severity of diabetic retinopathy," Diabetes and Metabolic Syndrome: Clinical Research and Reviews, vol. 12, no. 6, pp. 869$873,2018$.

[46] E. Ishizaki, S. Takai, M. Ueki et al., "Correlation between angiotensin-converting enzyme, vascular endothelial growth factor, and matrix metalloproteinase- 9 in the vitreous of eyes with diabetic retinopathy," American Journal of Ophthalmology, vol. 141, no. 1, pp. 129-134.e1, 2006.

[47] J. W. Kwon, J. A. Choi, and D. Jee, "Matrix metalloproteinase1 and matrix metalloproteinase- 9 in the aqueous humor of diabetic macular edema patients," PLoS One, vol. 11, no. 7, article e0159720, 2016.

[48] G. Mohammad and R. A. Kowluru, "Homocysteine disrupts balance between MMP-9 and its tissue inhibitor in diabetic retinopathy: the role of DNA methylation," International Journal of Molecular Sciences, vol. 21, no. 5, p. 1771, 2020.

[49] L. De Groef, L. Andries, K. Lemmens, I. Van Hove, and L. Moons, "Matrix metalloproteinases in the mouse retina: a comparative study of expression patterns and MMP antibodies," BMC Ophthalmology, vol. 15, no. 1, p. 187, 2015.

[50] I. van Hove, E. Lefevere, L. de Groef et al., "MMP-3 deficiency alleviates endotoxin-induced acute inflammation in the posterior eye segment," International Journal of Molecular Sciences, vol. 17, no. 11, p. 1825, 2016. 
[51] T. Hu, Q. You, D. Chen et al., "Inhibiting matrix metalloproteinase 3 ameliorates neuronal loss in the ganglion cell layer of rats in retinal ischemia/reperfusion," Neurochemical Research, vol. 41, no. 5, pp. 1107-1118, 2016.

[52] T. Hu, S. Wang, L. Zeng, K. Xiong, D. Chen, and J. Huang, "Regional expression of act-MMP3 contributes to the selective loss of neurons in ganglion cell layers following acute retinal ischemia/reperfusion injury," Current Eye Research, vol. 45, no. 5, pp. 591-603, 2020.

[53] E. Lefevere, M. Salinas-Navarro, L. Andries et al., "Tightening the retinal glia limitans attenuates neuroinflammation after optic nerve injury," Glia, vol. 68, no. 12, pp. 2643-2660, 2020.

[54] K. Cvitkovic, A. Sesar, I. Sesar et al., "Concentrations of selected cytokines and vascular endothelial growth factor in aqueous humor and serum of diabetic patients," Seminars in Ophthalmology, vol. 35, no. 2, pp. 126-133, 2020.

[55] S. Vujosevic and R. Simó, "Local and systemic inflammatory biomarkers of diabetic retinopathy: an integrative approach," Investigative Ophthalmology \& Visual Science, vol. 58, no. 6, pp. BIO68-BIO75, 2017.

[56] H. Chen, X. Zhang, N. Liao, and F. Wen, "Increased levels of IL-6, sIL-6R, and sgp130 in the aqueous humor and serum of patients with diabetic retinopathy," Molecular Vision, vol. 22, pp. 1005-1014, 2016.

[57] H. Noma, T. Mimura, K. Yasuda, and M. Shimura, "Role of inflammation in diabetic macular edema," Ophthalmologica, vol. 232, no. 3, pp. 127-135, 2014.

[58] A. G. Taşlipinar Uzel, N. UĞurlu, Y. Toklu et al., "Relationship between stages of diabetic retinopathy and levels of brainderived neurotrophic factor in aqueous humor and serum," Retina, vol. 40, no. 1, pp. 121-125, 2020.

[59] R. J. Hillier, E. Ojaimi, D. T. Wong et al., "Aqueous humor cytokine levels and anatomic response to intravitreal ranibizumab in diabetic macular edema," JAMA Ophthalmology, vol. 136, no. 4, pp. 382-388, 2018.

[60] K. Ishida, N. Yoshimura, M. Yoshida, and Y. Honda, "Upregulation of transforming growth factor-beta after panretinal photocoagulation," Investigative Ophthalmology \& Visual Science, vol. 39, no. 5, pp. 801-807, 1998. 